\title{
Acute Lantana camara poisoning in a Boer goat kid
}

\author{
Annalize Ide ${ }^{\mathrm{a}}$ and C L C Tutt ${ }^{\mathrm{b}}$
}

\begin{abstract}
Acute Lantana camara poisoning in a Boer goat kid is described. The animal was part of a flock of boer goats that was introduced from the Kalahari thornveld, where the plant does not occur, to an area where the plant grew abundantly. At necropsy, the animal was severely icteric, dehydrated and constipated, with hepatosis, distention of the gall-bladder and nephrosis, but no skin lesions. Histopathological findings of the liver confirmed moderate hepatosis with single-cell necrosis and bile stasis. The pathology is consistent with that described in acute Lantana poisoning in cattle, sheep and goats. The absence of photosensitisation may be attributed to relatively mild liver damage, or the rapid course of this toxicosis.
\end{abstract}

Key words: Boer goat, constipation, hepatosis, icterus, Lantana camara, nephrosis, photosensitisation.

Ide A, Tutt C L C Acute Lantana camara poisoning in a Boer goat kid. Journal of the South African Veterinary Association (1998) 69(1): 30-32 (En.). Department of Pathology, Faculty of Veterinary Science, University of Pretoria, Private Bag X04, Onderstepoort, 0110, South Africa.

\section{INTRODUCTION}

Lantana camara, a member of the Verbenaceae, is an exotic ornamental shrub $^{2-4,6}$ that is of particular importance in South Africa as a cause of cattle intoxication in the moist eastern parts of the country ${ }^{2-4,6}$. It was originally introduced from Central and South America and occurs commonly in many tropical and subtropical regions of the world ${ }^{6,14,15,17}$. The most important toxic principle of Lantana camara is lantadene A, a pentacyclic triterpene $\operatorname{acid}^{2-4,6,7,18}$. This substance has been shown to cause injury to the bile canalicular membranes, with subsequent cholestasis and hepatocellular damage ${ }^{12}$. Ingestion of the plant by cattle and sheep results in secondary photosensitivity, icterus and constipation, or in some cases, diarrhoea ${ }^{1-5,10,12,15}$. Two other members of the Verbenaceae, Lippia rehmannii and L. pretoriensis, also contain pentacyclic triterpene acids and may cause photosensitivity when dosed to ruminants $s^{4,5,13}$.

Reports of naturally occurring Lantana camara poisoning in goats are rare $\mathrm{e}^{10}$. Munyua et al. reported a case of acute

aDepartment of Pathology, Faculty of Veterinary Science University of Pretoria, Private Bag X04, Onderstepoort, 0110 South Africa.

${ }^{b}$ Department of Medicine, Faculty of Veterinary Science, University of Pretoria, Private Bag X04, Onderstepoort, 0110 South Africa. Present address: 'Rye', Park Road, Swanley, Kent, BR8 8AH, United Kingdom.

Received: October 1997. Accepted: January 1998.
L. camara poisoning in Kenya, when a group of calves, sheep and East African goats on zero-grazing were inadvertently exposed to the plant'. The clinicopathological features of acute and chronic lowdose L. camara poisoning in indigenous Zimbabwean goats were investigated by Obwolo et al. ${ }^{10,11}$. Acute poisoning was clinically characterised by anorexia, dehydration, ruminal stasis and severe icterus within 1-4 days of consuming the plant, but no photosensitisation occurred $^{9-11}$. The necropsy findings in this case included severe icterus, dehydration, constipation, hepatosis, distention of the gall-bladder and nephrosis. Moderate hepatosis with single-cell necrosis and bile stasis, as well as acute renal tubular necrosis, were confirmed histologically.

\section{CASE HISTORY}

During May 1996, a farmer near Pretoria, Gauteng, reported 3 mortalities in a flock of approximately 35 Boer goats recently introduced from the Kuruman area in the Northern Cape province. Necropsy of a 5-month-old Boer goat kid revealed icterus, dehydration, an enlarged, brown liver and a distended gall-bladder with multiple subserosal petechial haemorrhages at the gallbladder neck. The kidneys were pale with a yellow, glistening appearance and bulged at the cut surfaces. Moderate, diffuse pulmonary congestion was present. The colon and rectum were impacted with putty-like faeces. No skin lesions consistent with photosensitisation were present.

Specimens of the liver, kidneys, lung and spleen were collected in $10 \%$ buffered formalin for histology. Sections were routinely prepared and stained with haematoxylin and eosin, and Masson's trichrome ${ }^{8}$ method for connective tissue. Hepatocytes were diffusely and moderately swollen and possessed finely granular cytoplasm, with distinct cell borders. Some cells contained large intracytoplasmic vacuoles (Fig. 1). The cell nuclei varied in size and were hypochromatic, occasionally multinucleate, with finely stippled chromatin and one or more prominent nucleoli (Fig. 1). Several of the hepatocytes contained intracytoplasmic, yellowish-green bile pigment globules. Scattered hepatocytes exhibited coagulative necrosis in which karyorrhexis, karyopyknosis or karyolysis were variably present in addition to cytoplasm condensation and hypereosinophilia (Fig. 1). Hepatic cell plates were generally disrupted and the spaces of Disse moderately dilated. Mild bile duct proliferation and portal fibroplasia were present. Inflammatory cell infiltrates, consisting mostly of small numbers of neutrophils, lymphocytes and plasma cells, were present in the portal tracts and scattered throughout the parenchyma (Fig. 1).

Kidney lesions comprised areas of coagulative necrosis of the proximal tubules, predominantly in the cortex, but extending into the medulla (Fig. 2). Most of the remaining tubular epithelial cells were swollen, with finely granular cytoplasm (Fig. 2). Some proximal and distal convoluted tubules were dilated, while scattered tubules, especially at the cortico-medullary junction, contained yellowish-pink granular casts (Fig. 2). Other lesions included moderate, diffuse pulmonary congestion and multifocal atelectasis. The spleen was moderately diffusely congested.

During a farm visit, numerous Lantana camara shrubs were found in the garden and surrounding camps of the smallholding. The farmer had noticed some of the goats consuming Lantana 


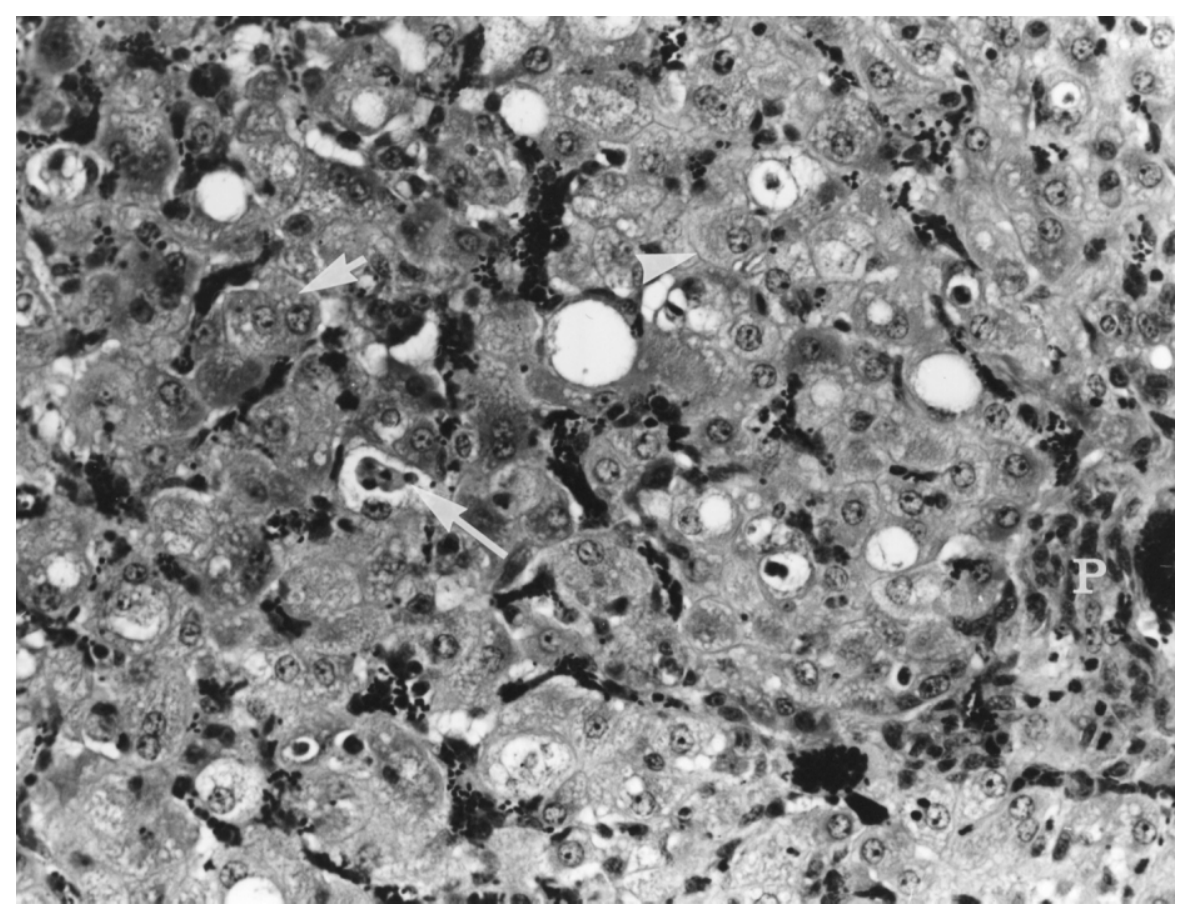

Fig. 1: Liver: hepatocytes are swollen with finely granular cytoplasm, distinct cell borders (arrowhead), and occasional large intracytoplasmic vacuoles. Occasional hepatocytes are multinucleate (short arrow). Randomly scattered hepatocytes show coagulative necrosis (long arrow). Note the portal cellular infiltrate $(P) . \mathrm{HE} \times 400$.

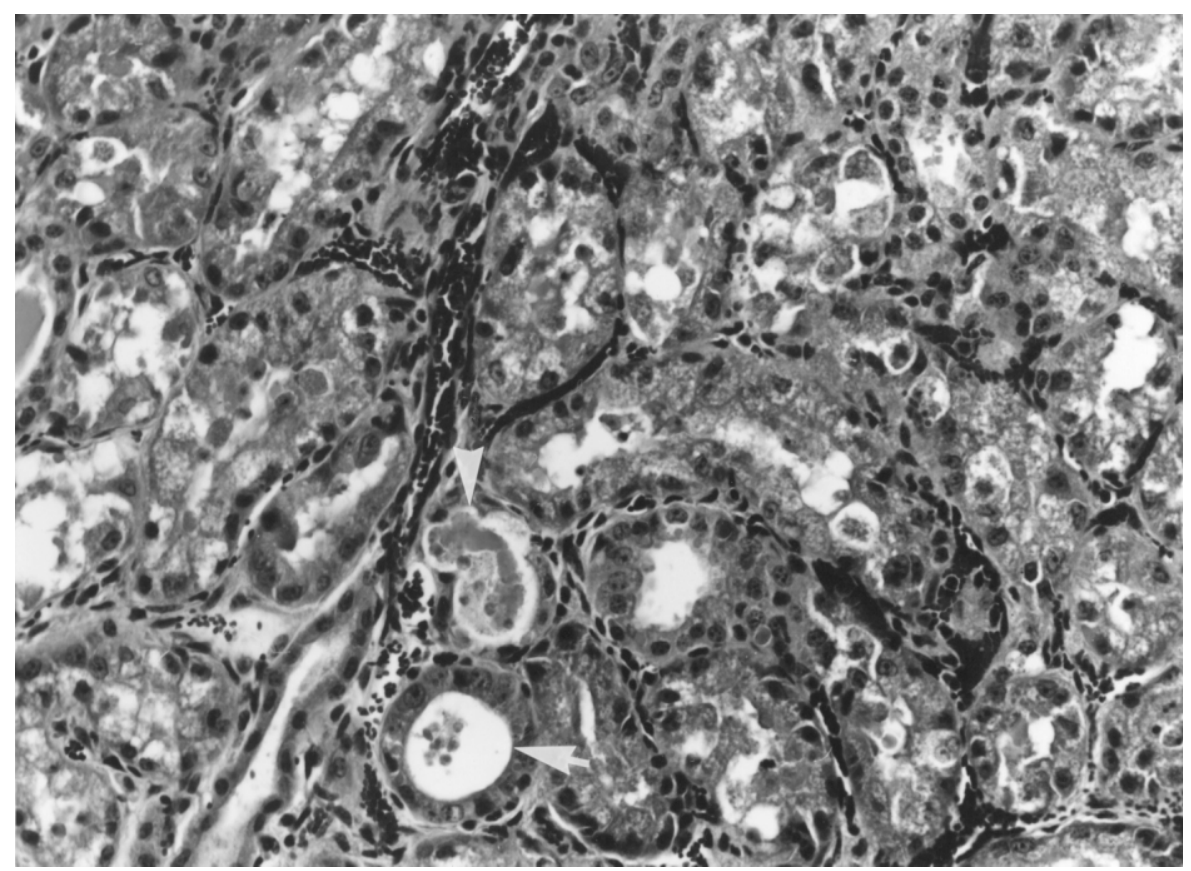

Fig. 2: Kidney: necrosis of epithelial cells in some proximal tubules is present (arrowhead). The remainder of the tubular epithelial cells show degenerative changes. There is also dilation of occasional tubules, some of which contain cellular casts (short arrow). HE $\times 400$.

camara plants in the garden and on closer examination it was clear that the plants had been browsed. Another species, identified by the National Botanical Institute, Pretoria, as Lantana mearnsii Moldenke var. latibracteola Moldenke, was also growing on the premises, although in far lower numbers than L. camara. This is an indige- poisoning in cattle, sheep and goats $^{2,3,5,5,11,16-18}$. The fact that photosensitisation was not present in this case correlates with previously described cases of experimental toxicity in goats in Zimbabwe ${ }^{10,11}$. It is believed that this may be attributed to relatively mild liver damage, insufficient to prevent elimination of phylloerythrin ${ }^{10}$. Alternatively, the course of the toxicosis may have been too acute for the animal to have been sufficiently exposed to sunlight.

Other toxic or infectious causes for the presence of icterus in the case examined were ruled out on the basis of the necropsy and histopathological findings. Although only 1 goat was presented for examination, it is possible that the other mortalities in the flock could also be attributed to L. camara poisoning, especially when the epidemiology of this case is taken into account.

To our knowledge, this is the 1st report of naturally occurring Lantana camara poisoning in goats in South Africa. Goats usually avoid eating these unpalatable plants. An important predisposing factor is the introduction of goats from an area where L. camara does not occur to a smallholding where the plant grew abundantly. In addition, the pasture was of poor quality at the time of introduction. Subsequent to our diagnosis, the premises were cleared of all L. camara shrubs and no further cases were reported.

\section{ACKNOWLEDGEMENTS}

We thank the National Botanical Institute, Pretoria, for assisting with plant identification and Mrs H. Smit of the photographic division of the Faculty of Veterinary Science, Onderstepoort, for processing of the photographs.

\section{REFERENCES}

1. Black H, Carter R G 1985 Lantana poisoning of cattle and sheep in New Zealand. New Zealand Veterinary Journal 33: 136-137

2. Fourie N, Van der Lugt J J, Newsholme S J, Nel P W 1987 Acute Lantana camara toxicity in cattle. Journal of the South African Veterinary Association 58: 173-178

3. Kellerman T S, Coetzer J A W 1985 Hepatogenous photosensitivity diseases in South Africa. Onderstepoort Journal of Veterinary Research 52: 157-173

4. Kellerman T S, Coetzer J A W, Naudé T W 1988 Plant poisonings and mycotoxicoses of livestock in southern Africa (1st edn). Oxford University Press, Cape Town

5. Kelly W R 1993 The liver and biliary system. In Jubb K V F, Kennedy P C, Palmer N (eds) Pathology of domestic animals (4th edn). Academic Press, California: 319-406

6. Louw P G J 1943 Lantanin, the active principle of Lantana camara L. Part I. Isolation and preliminary results on the determination of its constitution. Onderstepoort Journal of Veterinary Science 18: 197-202 
7. Louw P G J 1948 Lantadene A, the active principle of Lantana camara L. Part II. Isolation of lantadene $\mathrm{B}$, and the oxygen functions of lantadene A and lantadene B. Onderstepoort Journal of Veterinary Science 23: 233-238

8. Luna L G (ed.) 1968 Manual of the histological staining methods of the Armed Forces Institute of Pathology (3rd edn). McGraw Hill, New York

9. Munyua S J M, Njenga M J, Karitu T P Kimoro C, Kiptoon J E, Buoro I B J 1990 A note on clinical-pathological findings and serum enzyme activity in sheep, goats and Friesian calves with acute Lantana camara poisoning. Bulletin of Animal Health and Production in Africa 38: 275-279

10. Obwolo M J, Odiawo G O, Goedegebuure
S A 1990 Clinicopathological features of experimental Lantana camara poisoning in indigenous Zimbabwean goats. Zimbabwe Veterinary Journal 21: 1-7

11. Obwolo M J, Basudde C D K, Odiawo G O, Goedegebuure SA 1991 Clinicopathological features of experimental acute Lantana camara poisoning in indigenous Zimbabwean goats. Bulletin of Animal Health and Production in Africa 39: 339-346

12. Pass M A 1986 Current ideas on the pathophysiology and treatment of lantana poisoning of ruminants. Australian Veterinary Journal 63: 169-171

13. Rimington C, Quin J I 1935 The isolation of an icterogenic principle from Lippia rehmannii (Pears). South African Journal of Science 32: 142-151
14. Sanders D A 1946 Lantana poisoning in cattle. Journal of the American Veterinary Medical Association 109: 139-141

15. Seawright A A 1963 Studies on experimental intoxication of sheep with Lantana camara. Australian Veterinary Journal 39: 340-344

16. Seawright A A 1964 Studies on the pathology of experimental lantana (Lantana camara) poisoning in sheep. Pathologia Veterinaria 1: 504-529

17. Seawright A A, Allen J G 1972 Pathology of the liver and kidney in lantana poisoning of cattle. Australian Veterinary Journal 48: 323331

18. Seawright A A, Hrdlicka J 1977 The ora toxicity for sheep of triterpene acids isolated from Lantana camara. Australian Veterinary Journal 53: 230-235

\title{
Book review - Boekresensie \\ Proceedings of a symposium on lions and leopards as game ranch animals
}

\author{
Edited by J van Heerden
}

1997. South African Veterinary Association Wildlife Group, Onderstepoort, South Africa, 265pp. Price R100 (excl. postage). ISBN 1875088091.

The proceedings were made available to delegates at the annual Wildlife Group symposium held on the 24 and 25 October 1997. People from a number of disciplines and all experts in their field have made contributions to the proceedings. The topics covered included sociality and ecology of lions and leopards in the wild, lion genetics, census and capture techniques, handraising and veterinary management, a disease overview, parasites and trophy hunting.

The proceedings open with a biblical overview of lions by Pastor R Schmid. An international contribution by Dr Linda Munson (world-renowned veterinary pathologist with a special interest in wild carnivores) discusses the canine distemper virus outbreak in lions in the Serengeti and what the implications are for wild felid populations in South Africa and elsewhere. Prof. J du P Bothma gives us a glimpse into the life and times of the leopard, elusive creature that it is. He reiterated the importance of the leopard, and other large carnivores, in attracting tourists to Africa. Karen Trendler shares information on handrearing large carnivores and emphasises that they pose a unique set of problems especially once they have grown a 'little' and their hunting instincts become stronger. Dr Dewald Keet's paper discusses the role of the lion and cheetah in the epidemiology of tuberculosis in the Kruger National Park. This disease is becoming a serious threat to one of the largest natural lion populations in the world and has implications for the private landowner.

The proceedings provide a good source of up-to-date information on lions and leopards. It is a worthwhile acquisition for researchers, veterinarians, game ranchers or lay persons with an interest in large carnivores. After reading these proceedings one realises that the stability of Africa's natural lion and leopard populations is under threat, not only from 'man the predator' and loss of habitat but also from exotic and emerging new diseases like tuberculosis and canine distemper virus. While other species are effectively protected on smaller, private lands, large carnivores are not really suited to the game ranching scenario, emphasising the importance of large protected areas for the conservation of these species.

L Rasmussen Johannesburg Zoological Gardens 